\title{
AUTOMATIC DRAWING OF STEREOGRAPHIC NETS
}

\author{
A. VADON, D. RUER and R. BÄRO \\ Laboratoire de Métallurgie Structurale, Faculté des Sciences, Université de Metz, France
}

(Received January 10, 1973)

\begin{abstract}
The present paper describes a computer program for the automatic tracing of new stereographic nets aimed at the description of pole figures.
\end{abstract}

\section{INTRODUCTION}

The new, recently published stereo nets were designed to facilitate the description of pole figures. ${ }^{1}$ Their use has allowed us to develop a method based on the partial-fibre concept for analysing qualitatively rolling textures. ${ }^{2}$

These nets come in a standard execution: the radius is $10 \mathrm{~cm}$, the angle $\omega$ of the pole's sphere axis with the projection plane is a multiple of $5^{\circ}$, and the minimal angle between two parallels or two meridians is $10^{\circ}$.

For some studies, it may be useful to choose nets with different diameters, corresponding to angles $\omega$ which are not multiples of $5^{\circ}$. Besides these, it is sometimes desirable to have more precise nets, capable for measuring angular distances smaller than $10^{\circ}$ without interpolation.

The construction by hand of a net based on the published equations is very tedious. Programs for automatic tracing of stereographic projections and the Lambert projection have been published respectively by Starkey ${ }^{4}$ and by Wenk and Trommsdorff. ${ }^{5}$ However, the method used by these authors is based on the resolution of spherical triangles which for the use of the stereographic projections involves great complications and leads to programs of considerable length.

To overcome these difficulties, we have perfected a new program for automatic tracing, which produces quickly stereographic nets of any desired specifications.

\section{PRINCIPLE OF OPERATION}

The fundamental operation consists of the following:

a) the rotation by an angle $\alpha$ of a point $M$ on the reference sphere $(\Sigma)$ about an axis $\Omega^{\prime} \mathbf{\Omega}$ (Figure 1) transforms it into $M_{1}$. b) the stereographic projections of $M$ and $M_{1}$ (and of the arc $M M_{1}$ ) are, respectively $M^{\prime}$ and $M_{1}^{\prime}$ (and the $\operatorname{arc} M^{\prime} M_{1}^{\prime}$ ).

The angles $\theta=\left(\mathbf{O}_{z}, \mathbf{O} \Omega\right)=\pi / 2-\omega$ and $\psi=$ $\left(\mathbf{O}_{x}, \mathbf{O O}^{\prime}\right)$ define the position of the axis $\boldsymbol{\Omega}^{\prime} \boldsymbol{\Omega}$. The arc $\eta$ represents the colatitude of points $M$ and $M_{1}$ (measured on the sphere of axis $\boldsymbol{\Omega \Omega}^{\prime}$ ).

The coordinates of $M$ can be expressed in the form of:

$$
\begin{aligned}
& X_{M}=R \sin (\theta-\eta) \cos \psi \\
& Y_{M}=R \sin (\theta-\eta) \sin \psi \\
& Z_{M}=R \cos (\theta-\eta)
\end{aligned}
$$

The coordinates of $M_{1}$, transformed from $M$ by the rotation $(\mathbf{O} \Omega, \alpha)$, are obtained by:

$$
\left[\begin{array}{l}
X_{M 1} \\
Y_{M_{1}} \\
Z_{M_{1}}
\end{array}\right]=A\left[\begin{array}{c}
X_{M} \\
Y_{M} \\
Z_{M}
\end{array}\right]
$$

where $A$ is a matrix of rotation which can be decomposed into a sum of three matrices containing the terms of the angle $\alpha$ and the components $C_{1}$, $C_{2}, C_{3}$ of the axis $\mathbf{0 \Omega} .^{3}$ Matrix $A$ is thus written as:

$$
\begin{aligned}
A= & \cos \alpha\left[\begin{array}{lll}
1 & 0 & 0 \\
0 & 1 & 0 \\
0 & 0 & 1
\end{array}\right] \\
& +(1-\cos \alpha)\left[\begin{array}{lll}
C_{1}^{2} & C_{1} C_{2} & C_{1} C_{3} \\
C_{2} C_{1} & C_{2}^{2} & C_{2} C_{3} \\
C_{3} C_{1} & C_{3} C_{2} & C_{3}^{2}
\end{array}\right] \\
& +\sin \alpha\left[\begin{array}{ccc}
C & -C_{3} & C_{2} \\
C_{3} & 1 & C_{1} \\
-C_{2} & C_{1} & 0
\end{array}\right]
\end{aligned}
$$


To obtain all the $M_{1}$ points located on the parallel passing through $M$ one can just let $\alpha$ vary from 0 to $2 \pi$ (See in annex: subroutine ROTAS).

The stereographic projection $M^{\prime}$ of point $M$ on the $x 0 y$ plane can be obtained by expressing that vectors $\mathbf{P M}^{\prime}$ and $\mathbf{M}^{\prime} \mathbf{M}$ are colinear (Fig. 1)

$$
\begin{aligned}
X_{M^{\prime}} & =\frac{Z p X_{M}}{Z p-Z_{M}} \\
Y_{M^{\prime}} & =\frac{Z p Y_{M}}{Z p-Z_{M}}
\end{aligned}
$$

The matrix of relation (5) can be obtained when one replaces in the matrix of relation (3) the components of $O \Omega$ by the components of $O E$ which is perpendicular to plane $\left(\mathbf{O} \Omega, \mathbf{O M}_{1}\right)$. The stereographic projection of the meridians can thus be derived directly from relation (5).

Figure 2 shows a net for which $\omega=\pi / 2-\theta=$ $32.5^{\circ}$ and $\psi=0^{\circ}$, with the parallels and meridians separated by angles of $10^{\circ}$. The stereographic projection of the hemisphere under the projection plane is drawn by dots, the distance between two dots corresponding to $1^{\circ}$. The drawing has been

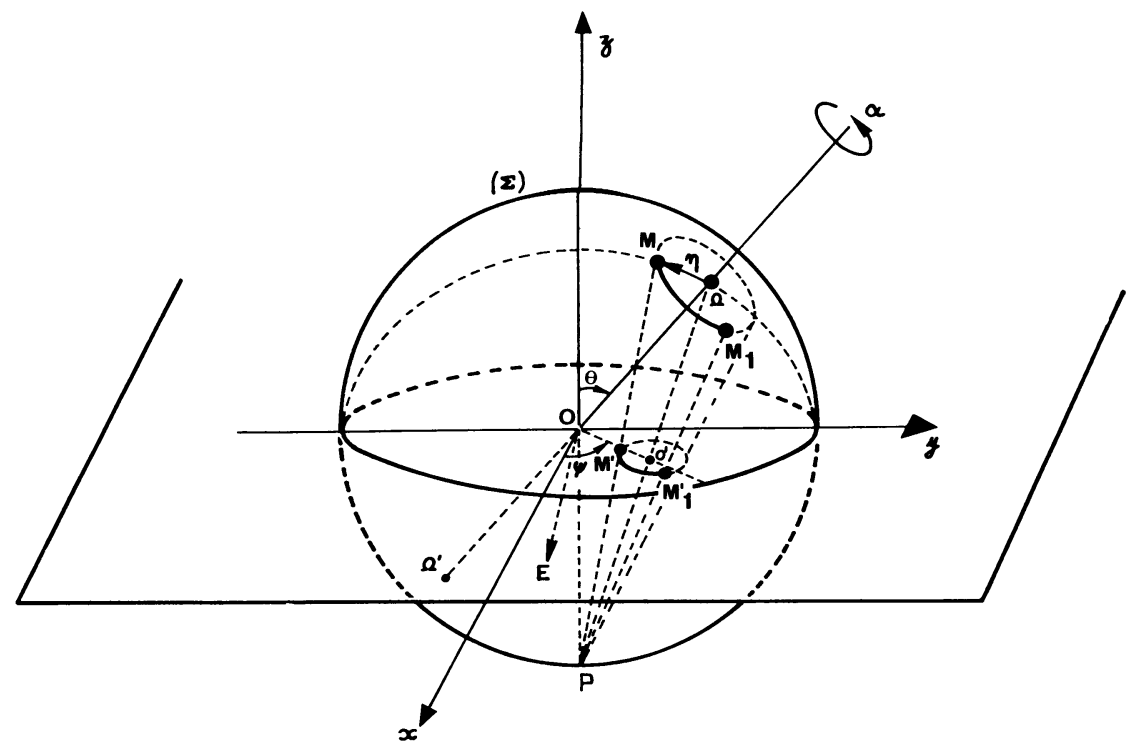

FIGURE 1 Stereographic projection of a pole describing the parallel of latitude $(\pi / 2-\eta)$ on the sphere of axis $\Omega^{\prime} \Omega$. OE is the axis of the meridian on which $M$ is located. $\alpha$ is the difference in longitude of $M_{1}$ and $M_{1}^{\prime}$.

where $Z p=\mp R$, depending upon whether the height of $M$ is positive (as in Fig. 1) or negative.

The stereographic projection of the parallels can now be obtained by making $\eta$ to vary.

For the particular value of $\eta=\pi / 2$ relation (2) gives the projections of the vectors $\mathrm{OE}$ which are perpendicular to $\mathbf{O \Omega}$ (Figure 1). Each of these vectors is the axis of one meridian of diameter $\boldsymbol{\Omega}^{\prime} \boldsymbol{\Omega}$ and longitude $\alpha$. So the coordinates of any point $M_{1}$ of a meridian are given by:

$$
\left[\begin{array}{c}
X_{M_{1}} \\
Y_{M_{1}} \\
Z_{M_{1}}
\end{array}\right]=A^{\prime}\left[\begin{array}{c}
X_{\Omega} \\
Y_{\Omega} \\
Z_{\Omega}
\end{array}\right]
$$

done automatically by a BENSON 120 plotter conducted by an IBM 1130 computer which was programmed in FORTRAN IV. The absolute error in the drawing of a net is $0.1 \mathrm{~mm}$. The net shown in Figure 2 has been obtained in about 30 minutes. The radius $R$ of the net can be chosen at will up to $35 \mathrm{~cm}$. The ordinogram is given in Figure 3 and the program in the Appendix.

\section{ACKNOWLEDGMENT}

We express our sincere gratitude to Monsieur P. Maurice, Director of the Ecole Nationale d'Ingénieurs de Metz for allowing us to use the computer and the plotter of this Institute. 


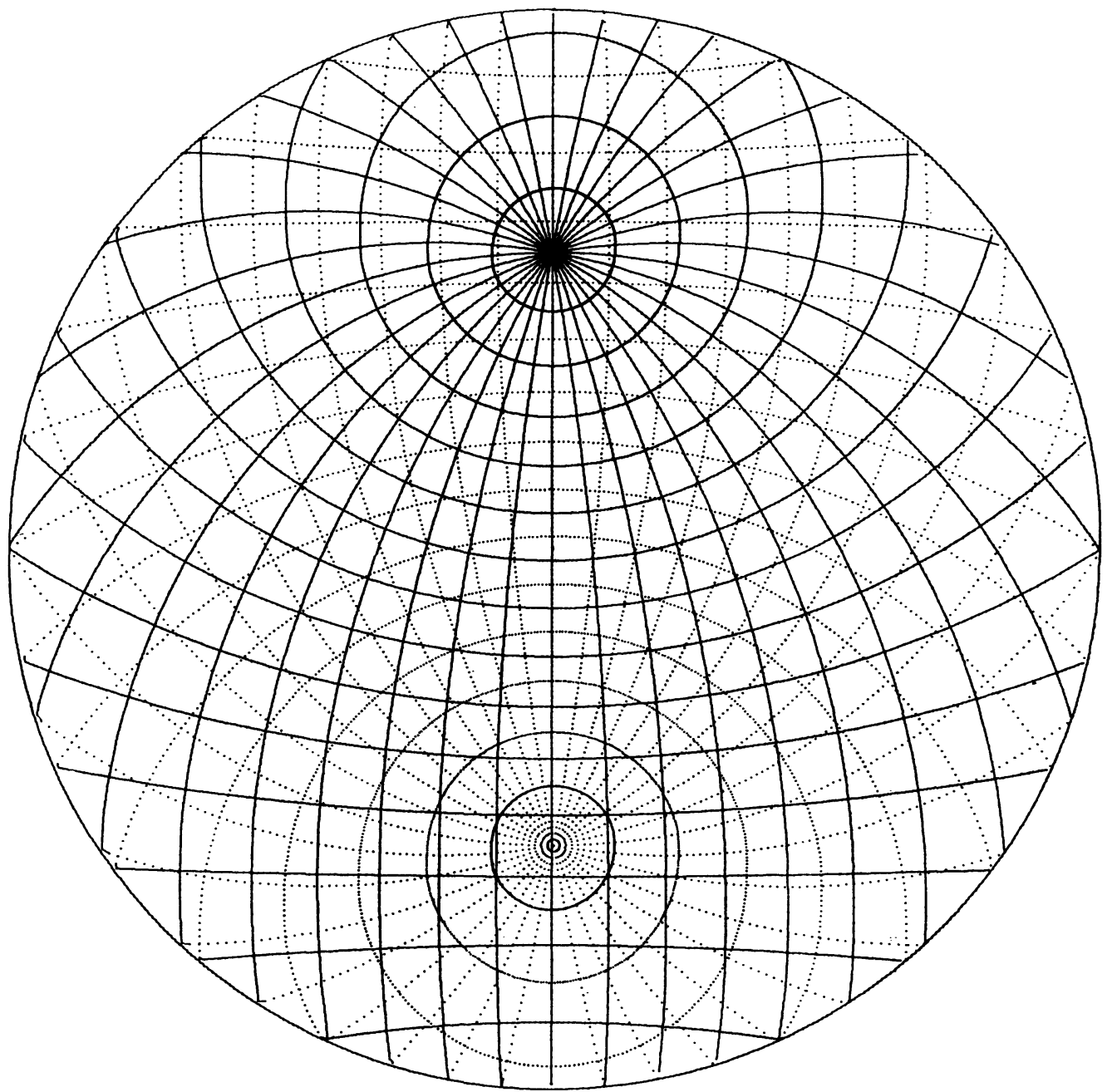

FIGURE 2 Stereographic net corresponding to $\omega=32.5^{\circ}$. On the dotted lines the angular distance between two dots is $1^{\circ}$. 

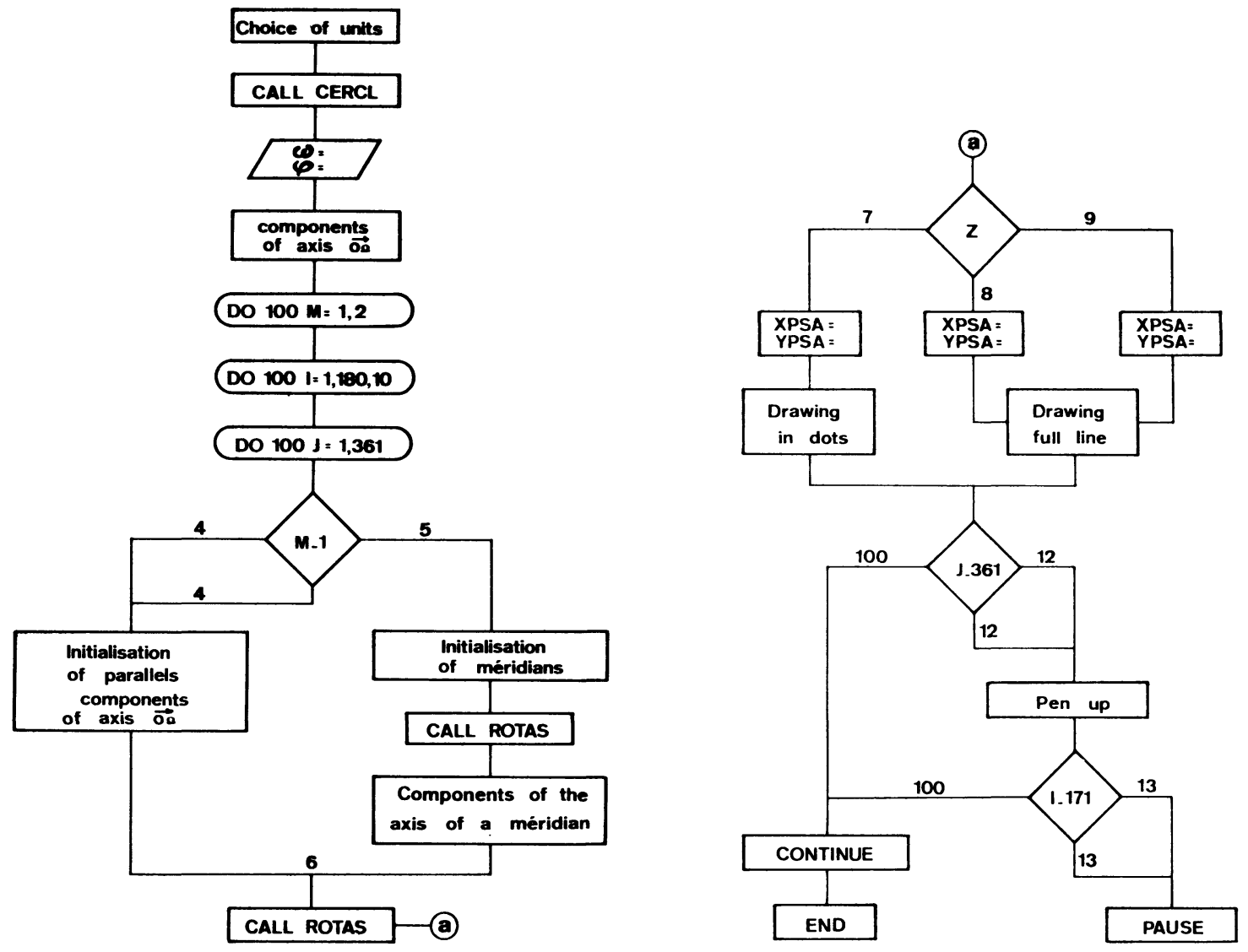

FIGURE 3 Ordinogram.

\section{REFERENCES}

1. D. Ruer and R. Baro, J. Appl. Cryst. 4, 321 (1971).

2. D. Ruer, A. Vadon and R. Baro, to be published.

3. G. A. Korn and T. M. Korn, Mathematical Handbook for Scientists and Engineers (McGraw Hill Book Company, New York, 1968) p. 473.
4. J. Starkey, in Experimental and Natural Rock Deformation, P. Paulitsch, Ed. (Springer Verlag, Berlin/ Heidelberg/New York, 1970) pp. 38-50.

5. H. R. Wenk und V. Trommsdorff, Koordinatentransformation, Mittelbare Orientierung, Nachbarwinkelstatistik. Beiträge zur Mineralogie und Petrographie 11, 559 (1965). 


\section{APPENDIX}

\section{Program of drawing}

CFCICE GF LNITS

REACI $(2,1) \cup X$

FCRNAT (FIC.b)

CALL:SCALF UUX,UX, O., O.

$P I=3.1415926$

$R=1$.

THE RACILS CF THE REFERENCE SPHERE IS TAKEN FOR UNIT

CRAHING CF PRCJECTICN CIRCLE

CALL. CERCL(C.,C., L, LX)

REACINE CF INPLTS

REAC $(2,2)$ CNEEA, PS

FCRNAT $(2 F 1 C . S)$

IRITE $(5,3)$ CNECA, PSI

3 FCRMAT (/1OX, 'CMEGA $=1, F 5.2,5 X, 1$ PSI $=1, F 5.2)$

TETA $=9$ C. - CNË̈A

TETA $=$ TETA $A$

PSI $=$ PSI $* P$

\section{CCNPCNENTS CF THE AXIS CF RCTATICN}

\section{$S P=\operatorname{SIN}(P S I)$}

$C P=C D S(P S I)$

$X[=S I N(T E T A) * C P$

$Y C=S I N(T E T A) * S P$

$\angle C=\operatorname{CCS}(T E T A)$

CO $100 \quad \mu=1,2$

CC $100 \quad I=1,180,10$

CC 1 CC $J=1,361$

IF $(N-1) 4,4,5$

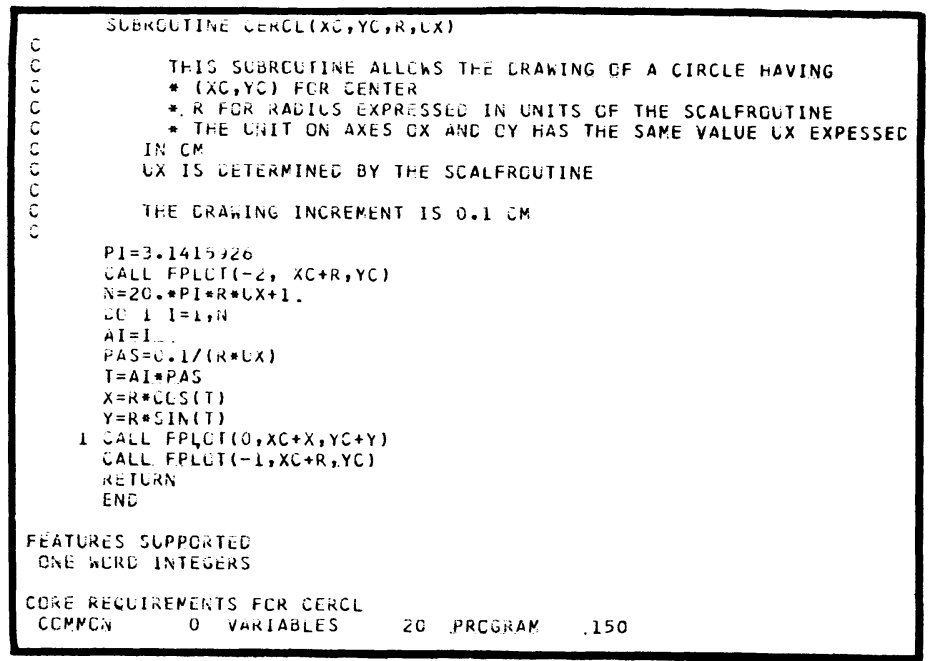

inItIALISATIUN ANE CCMPCNENTS GF THE AXIS CF THE PARALLELS

$4 X=S I N(T E T A-F L C A T(I-1) * P) * C P$

$Y=S I N(T E I A-F L L A T(I-1) * P) * S P$

$Z=\operatorname{CCS}(T E T A-F L C A I(I-1) * P)$

$\therefore 1=x[$

$C 2=Y L$

$C 3=25$

60 IC 6

$c$

INITIALISATICN ANC CCMPCNENTS CF THE AXIS CF THE NERICIANS

$5 X=X c$

$X=X C$
$Y=Y C$

$Y=Z C$
$X E=S P$

$\begin{array}{ll}X E & =S P \\ Y E & =-C P\end{array}$

$Y E=-C$

CALL.RCTAS $(X C, Y C, \angle C, F L C A T(1-1) \approx P, X E, Y E, Z E)$

$C I=X E$

$\therefore 1=X E$

$\therefore 2=Y E$

c

RCIATICN, SIERECGRAPHIC PRCJECTION ANC CRAWING

6 CALL RCTAS $(C 1, C 2, C 3, F L C A T(J-1) * P, X, Y, Z)$

IE $(\angle) T, Q, Y)$

$\operatorname{IE}(\angle), 7,8,\{i$
$X P S A=X * R /(R-Z)$

$Y P S A=Y * R /(R-Z)$

CALL FFLCT $(1, X P S A, Y P S A)$

CALL FPLCII-2,XPSA,YPSA)

GC TC 11

8. $X P S A=X$

$Y P S A=Y$

ED TC 10

$X P S A=X: R /(R+L$

$Y P S A=Y * R /(R+Z)$

10 CALL FPLCTI-2,XPSA,YPSA)

11 IF $(J-3 t 1) 1 C C, 12,12$

12 CALL FPLCI $(+1, X P S A, Y P S A)$

IF $(1-171) 1 C C, 13,13$

I NINLS THE LAST VALLE CF I

13 PALSE

ICO CONTINLE

CALL EXI

ENC

FEATURES SLPPCRTEL

CNE WCRE INTEEERS

ICCS

CQRE RECUIRENENTS FCR VT2

COAPON O VARIABLES

JUEKLLTIRE RLTAS(CL,C¿,C $, A L P H A, X, Y, Z)$

THIS SUIRCLTINE ALLCWS TC CALCLLATE THE CCCRDINATES CF MI IRANSFURMEL FRCM $M(X, Y, Z)$ BY A RUTATION HAVING.

* flir axis the cCMpenents C1, CZ,C3

- for aivile alpha in radians

AFTEK ITE KCTATICN ITE CCCRCINATES ARE CALLED $X, Y, Z$

$S B=S I N(A L P H A)$

$G E=C C S(A L P H A)$

$S 1=C 1 * S_{L}$

$52=C 2 * S i$

$53=C 3 * S E$

$\therefore C a=1 .-6 a$

$C 12=C 1 * C 2 * C C$

$C 13=C 1 * C 3 * C C D$

$C 23=C 2 * C 3 * C L i$

$X A=(C E+C 1 * C A * C C E) * X+(C 1<-53) * Y+(C 13+52) * Z$

$Y A:=(C 12+S 3) * X+(C E+C Z * C 2 * C C B) * Y+(C<3-S 1) * Z$

$\angle A=(C 13-52) * X+(C 23+S 1) * Y+(C B+C 3 * C 3 * C C B) * Z$

$X=x A$

$Y=Y A$

$Z=Z A$

RETLR:N

CNC

FLATLRES SLPPENTED

L.AE ICRC. I.VIEUERS

CLAE REQLIREMENIS FLR RCTAS

CEMCi $O$ VAKLIAGLES 20 FRCGKAM 210 